
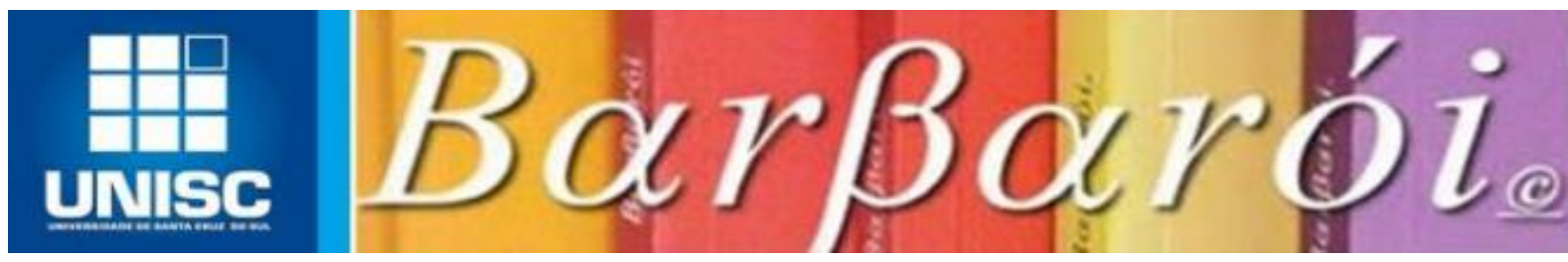

\title{
CONTRIBUIÇÕES DOS SABERES MÉDICOS E CRIMINOLÓGICOS NA EMERGÊNCIA DA PSICOLOGIA JURÍDICA BRASILEIRA
}

DOI: http://dx.doi.org/10.17058/barbaroi.v2i52.13253

\author{
Rafaela Sousa Caldas \\ Universidade Federal de Goiás - UFG - Brasil \\ Tiago Cassoli \\ Universidade Federal de Goiás - UFG - Brasil
}

\section{Resumo}

Inicialmente destinada como saber auxiliar à prática da justiça, a psicologia jurídica estruturou-se no Brasil a partir do jogo de dupla qualificação médica e judiciária no qual a figura do criminoso passou a prevalecer sobre a apreciação do delito, movimento que uniu práticas disciplinares e jurídicas aos discursos médicos, psiquiátricos e psicológicos. O presente trabalho busca demarcar no percurso histórico de desenvolvimento da psicologia jurídica brasileira suas articulações junto a saberes como a psiquiatria e a criminologia ao longo de um projeto societário disciplinar e normalizador que refletiu no aumento das atividades diagnósticas e avaliativas, ainda hoje as principais atividades endereçadas aos psicólogos jurídicos. Na tentativa de promover reflexões e possibilitar novas análises sobre o tema, são problematizadas neste trabalho as relações entre saber-poder no processo de emergência e estruturação da Psicologia Jurídica no Brasil a partir de certas análises produzidas por Michel Foucault. Trata-se, principalmente, de uma tentativa de se valer de alguns dos elementos conceituais construídos pelo autor como dispositivos para uma análise crítica das relações entre práticas de conhecimento e práticas de poder assumidas pela psicologia jurídica brasileira, problematizando suas regulamentações sociais e urgências políticas enquanto saber e nova tecnologia de poder produzida na modernidade.

Palavras-chave: Psicologia Jurídica, Psiquiatria, Criminologia 


\section{Introdução}

A vinculação dos saberes psicológicos e psiquiátricos às práticas jurídicas foi se consolidando no Brasil no decorrer do século XX em meio a cenários e forças sociopolíticas constituintes da modernidade que adquiriram certas especificidades no caso brasileiro. Inicialmente destinada como saber auxiliar à prática da Justiça, a psicologia jurídica estruturou-se no Brasil a partir do "jogo de dupla qualificação médica e judiciária” no qual a figura do criminoso passou a prevalecer sobre a apreciação do delito, unindo práticas disciplinares e jurídicas aos discursos médicos, psiquiátricos e psicológicos (FOUCAULT, 2010).

Assim, o surgimento e a difusão da psicologia jurídica no Brasil estiveram intimamente relacionados com a ampliação e legitimação dos saberes médicos, em especial, da psiquiatria. A institucionalização dos saberes médicos nos hospitais e, posteriormente, nos asilos psiquiátricos e prisões, protagonizou o início do desenvolvimento dos saberes psis. Atrelada às práticas de controle social e normalização, a psiquiatria se afirmou como prática social muito antes de se legitimar enquanto saber sistematizado e foi no decorrer do seu exercício e a fim de instrumentalizá-la que a psicologia se inseriu no universo jurídico.

Sob o impacto desses saberes, assistiu-se no cenário judicial o desenvolvimento e a apropriação dos discursos da criminologia, sobretudo das contribuições lombrosianas, pela Escola Positiva de Direito Penal. Amparando-se em uma pretensa "racionalidade científica" essa corrente de pensamento estabelecia novas formas de entendimento sobre a criminalidade e a gênese do crime, depositando nos fatores individuais a sua determinação e estabelecendo o tratamento científico do indivíduo como forma de proteger a sociedade. O saber criminológico ao buscar "conhecer" o indivíduo para controlá-lo refletiu no aumento das atividades avaliativas e diagnósticas, através da instrumentalização de técnicas e saberes da psiquiatria e da psicologia.

Dessa forma, a relação entre psicologia e Justiça remonta a um passado em que agentes do conhecimento psicológico eram chamados a responder sobre o funcionamento mental do criminoso. O diagnóstico psicológico serviria para melhor controlar e classificar o indivíduo na medida em que possibilitava, dentre outras terapêuticas, a sua institucionalização. Atrelado ao saber psiquiátrico, a gênese da psicologia jurídica no Brasil se deu na forma instrumental de auxílio aos médicos psiquiatras na identificação tanto do criminoso, como do doente mental e da criança desviante (JACÓ-VILELA et al, 2005). Posteriormente, destinou-se ao estudo da veracidade dos testemunhos, seguido do ingresso formal dos psicólogos em instituições jurídicas 
da área penal e em espaços relacionados ao contexto Cível (BRITO, 2005, 2012). Atualmente, presencia-se uma grande difusão das demandas destinadas ao psicólogo jurídico, tais como: a mediação de conflitos, avaliação do dano psíquico, o estabelecimento e acompanhamento das medidas socioeducativas, avaliações de instituições jurídicas, dentre outras (ARANTES, 2011; ROVINSKI, 2007, 2009; BRITO, 2012).

Dentre essas demandas, as atividades avaliativas e diagnósticas ainda figuram como as mais predominantes no exercício profissional do psicólogo no âmbito jurídico (LAGO, et al; 2009; ARANTES, 2004; 2011; CAIRES, 2003; SILVA, 2003; ROVINSKI, 2007). Alvo de intensas discussões seja sobre o seu caráter instrumental e eficácia (ROVINSKI 2007, SILVA, 2003 CAIRES, 2003, GAVA, 2012), seja quanto ao projeto societário e político ao qual se articula (BRANDÃO \& GONÇALVES, 2011; COIMBRA, 2003; ARANTES, 2011; RAUTER, 2003; BRITO, 2012) a atividade pericial e a produção de relatórios, pareceres e laudos psicológicos para a justiça apresenta-se nas bibliografias atuais da área como uma das principais colaborações técnicas da psicologia à instância jurídica.

O presente trabalho tem como objetivo demarcar no percurso histórico de desenvolvimento da psicologia jurídica brasileira suas articulações junto a saberes como a psiquiatria e a criminologia, num projeto societário disciplinar e normalizador que refletiu no aumento das atividades diagnósticas e avaliativas a serviço do controle social, que ainda se mantém nos dias atuais. Como objetivos específicos têm-se o estudo das condições de emergência da psicologia jurídica a partir de problematizações dos saberes médicos, a análise e discussão dos saberes psiquiátricos e psicológicos no âmbito jurídico; a sinalização de algumas contribuições da criminologia no cenário nacional e no desenvolvimento das técnicas diagnósticas e avaliativas e, por fim, a análise da inserção formal do psicólogo nos aparelhos da Justiça brasileira.

A recuperação da dimensão histórica do desenvolvimento da psicologia jurídica no Brasil figura como duplo recurso metodológico que promove, além do resgate dos quadros epistemológicos e papéis políticos assumidos por esse saber ao longo do tempo, uma reflexão crítica sobre as suas (des)continuidades. Deste modo, entende-se que recorrer à forma como a psicologia jurídica se afirmou como saber possibilita ultrapassar a visão de um conhecimento que se desenvolveu natural e continuamente, introduzindo importantes aspectos que se entrelaçaram nesse percurso e que contribuíram para o seu arranjo atual. 


\section{Perspectiva metodológica}

Na tentativa de promover reflexões e possibilitar novas análises sobre o tema serão utilizados os instrumentais analíticos da genealogia produzidos Michel Foucault. $\mathrm{O}$ trabalho produzido por Foucault, ao percorrer diferentes campos de saber e transitar por diferentes formas de análises superou as divisões disciplinares tradicionais e lançou mão de leituras inéditas sobre as nomeadas Ciências Humanas. O projeto genealógico estruturado por Foucault busca ativar os saberes locais, desqualificados e descontínuos, em sua historicidade e táticas operativas, em oposição a uma instância teórica unitária, ordenada e hierarquizada que se destinaria a produção de um conhecimento verdadeiro. Dessa forma, figura como uma espécie de uma "anti-ciência", que se utiliza do rastreio da insurreição de saberes contra os poderes centralizadores ligados ao funcionamento de um discurso cientifico organizado, inquestionável e verdadeiro, combatendo os seus efeitos intrínsecos de poder (FOUCAULT, 1979, p. 171).

Para Foucault os saberes, compreendidos como materialidade, práticas e acontecimentos, são dispositivos políticos articulados a diferentes formações sociais (FOUCAULT, 1979). A análise dos saberes implica numa análise do poder dado que são por ele constituídos à medida que as relações de poder se associam e se estabelecem juntamente com a produção, circulação e efeitos dos discursos. Para o autor, o poder tomado na sua positividade, produz domínios específicos de objetos, estes pautados numa eficácia estratégica (MACHADO, 1979).

$\mathrm{Na}$ tentativa de compreender os saberes enquanto estratégia de poder convém retomar a noção de poder disciplinar, enquanto mecanismo que permite estabelecer uma estreita relação entre as tecnologias de poder e os novos saberes normalizadores que surgem com a modernidade.

Foucault, na obra Vigiar e Punir (1977) constrói uma genealogia das práticas penais francesas desde a época clássica até o século XIX, analisando no interior das suas transformações o papel central ocupado pela prisão no regime das penalidades modernas. Questionando-se sobre a funcionalidade da prisão enquanto pena por excelência, que se destina não mais ao açoite do corpo, tal como a prática do suplício ou castigos simbólicos, mas a "alma" do detento, mostra 
como as práticas disciplinares da prisão constroem uma tecnologia de poder que se ramifica a outras esferas sociais.

A análise das punições realizadas por Foucault (1977) se deteve, principalmente, na relação entre as formas de saber e as práticas de poder. O percurso genealógico construído apontou a existência de uma estreita relação entre as tecnologias de poder disciplinares e os novos saberes normalizadores que surgem com a modernidade. O poder disciplinar, ao buscar transformar os indivíduos, torná-los úteis, dóceis e produtivos, se estrutura junto a novos saberes que introduzem um conhecimento científico no campo das punições, tais como: a psiquiatria, a antropologia criminal e a criminologia. Para o autor, esses saberes normalizadores, acabam por desempenhar o papel de novas tecnologias do poder voltadas antes para a transformação do individuo, do que para a construção de novos conhecimentos.

Em outro momento, Foucault assevera a relação entre os saberes normalizadores e a produção de novas tecnologias de poder, inserindo nesse contexto os saberes psicológicos:

...um novo saber, de tipo totalmente diferente, um saber de vigilância, de exame, organizado em torno da norma pelo controle dos indivíduos ao longo de sua existência. Esta é a base do poder, a forma de saber-poder que vai dar lugar não às grandes ciências de observação como no caso do inquérito, mas ao que chamamos de ciências humanas: Psiquiatria, Psicologia, Sociologia etc. (FOUCAULT, 1996, p.88)

A partir da relação entre os saberes normalizadores e as diferentes estratégias do exercício de poder, o presente trabalho tecerá reflexões e análises sobre a psicologia jurídica enquanto saber e prática social que se insere no judiciário, reafirmando articulações anteriores de controle e normalização dos indivíduos, sob uma pretensa cientificidade. Trata-se, principalmente, de uma tentativa de se valer dos elementos conceituais construídos por Foucault para uma análise crítica das relações entre práticas de conhecimento e práticas de poder assumidas pela psicologia jurídica brasileira, especialmente no contexto criminal, problematizando suas regulamentações sociais e urgências políticas enquanto saber e nova tecnologia de poder produzida na modernidade.

A ausência de um diálogo sistemático e imediato com as fontes documentais e historiográficas dos períodos analisados constitui ressalva significativa à abordagem histórica adotada neste trabalho, que diante da dificuldade de tal empreitada se limitou a dialogar com trabalhos que se dispuseram a investigar a emergência histórica dos saberes e práticas psis, especialmente da psicologia jurídica, inspirados no instrumental foucaultiano. A escolha do 
material bibliográfico decorreu de investigações anteriores ${ }^{1}$ em que foram mapeadas as produções sobre a prática pericial no contexto criminal, em detrimento dos processos cíveis, nas diferentes bases de dados que integram a Biblioteca Virtual em Saúde- BVS PSI a partir de descritores específicos, e em livros especializados no tema.

A seleção e análise do material encontrado possibilitaram o contato com trabalhos críticoreflexivos que problematizavam o papel da perícia no judiciário, sua operacionalização e efeitos. Estes, apesar de pouco numerosos, indicavam caminhos de análises possíveis, sendo comum a presença de alguns elementos que integram o pensamento de Foucault. A coletânea de artigos que compõem a obra de Brandão \& Gonçalves (2011), que não se limitam apenas ao tema pesquisado, consistiu na principal contribuição para a realização do recorte que viria a caracterizar este trabalho.

Do primeiro levantamento bibliográfico realizado foram mantidas as referências que definiam a atividade pericial e aquelas que problematizavam o papel da perícia psicológica no contexto jurídico. Em momento posterior, foram utilizadas as mesmas bases de dados para investigar artigos de periódicos que trouxessem em seu título ou corpo alguma referência à história da psicologia jurídica no Brasil, totalizando apenas quatro trabalhos, e três resumos de livros; Assim, a partir da análise desses trabalhos e da leitura de certas obras de Foucault que integram a nomeada fase genealógica, foram estabelecidas as principais articulações disciplinares da psicologia jurídica brasileira ao longo do tempo.

\section{Da Medicina Social à Psicologia Jurídica no Brasil}

Como apresentado introdutoriamente, é no encontro entre medicina e direito que se tem uma das condições de emergência da psicologia jurídica brasileira. Esta aliança se consolidou ao longo dos séculos XIX e XX em meio a cenários e forças sociopolíticas constituintes da modernidade, que adquiriram certas especificidades no caso brasileiro. De maneira mais

\footnotetext{
1 Durante o período de graduação realizei dois estágios em instituições jurídicas: o primeiro junto à equipe técnica em psicologia do Ministério Público Estadual, nos anos de 2013 e 2014, e o segundo na junta médica oficial do Tribunal de Justiça do Estado de Goiás, em 2015. Destas experiências decorreram contatos diversos com as práticas em psicologia jurídica e com as principais bibliografias da área. Sobretudo no último campo de estágio, a atividade pericial consistia na principal demanda destinada à equipe, fato que culminou na realização de pesquisa institucional sobre a perícia psicológica no contexto criminal, e que possibilitou conexões importantes para o que posteriormente constituiria o objeto de estudo deste trabalho.
} 
particularizada, foi com discursos e práticas que integraram o campo da psiquiatria e da criminologia que essa articulação se solidificou fazendo com que as práticas avaliativas e diagnósticas no campo penal ganhassem certo protagonismo.

A psiquiatria, no entanto, surge como desdobramento da medicina social, perspectiva presente no período republicano em que se tem a circulação dos saberes médicos como principal interventor diante dos desarranjos sociais e individuais, como saber capaz de reconhecer, prevenir e tratar as anormalidades. Demarcar historicamente os jogos de saberes e poderes que culminaram na estruturação da psicologia jurídica enquanto prática profissional e conhecimento especializado requer, portanto, a análise dos impactos das 'ciências médicas' no cenário nacional e seus embates com outros campos de saber.

Obra pioneira sobre o tema, o livro Danação da norma: a medicina social e constituição da psiquiatria no Brasil, escrito em 1978, por Roberto Machado e colaboradores, inaugura os estudos brasileiros sobre a medicina e a psiquiatria como instrumentos de poder. De inspiração foucaultiana, a obra se destina ao estudo da história dos saberes médicos na sociedade brasileira através de diferentes fontes discursivas- leis, regulamentos, ofícios, alvarás, cartas, jornais, teses, panfletos- e os seus efeitos de poder. Analisa os conceitos básicos da medicina social e da psiquiatria brasileira enquanto saberes que sustentaram práticas sociais e que se constituíram em interseção com o Estado no seu projeto de controle social; processo denominado pelos autores por 'medicalização da sociedade'?

Segundo os autores, a prática médica ao longo do século XVIII esteve diretamente relacionada à físcalização da "arte de curar" ${ }^{3}$. Em Portugal a autoridade médica compunha o dispositivo político-administrativo da monarquia; destinado ao cargo de Cirurgião-mor dos Exércitos, o médico era encarregado da fiscalização do exercício das artes médicas e cirúrgicas. Foi com contornos semelhantes que durante o estabelecimento da administração portuguesa no Brasil foram criados os cargos de físico-mor e cirurgião-mor com o objetivo de garantir o efetivo exercício da fiscalização das práticas médicas, devendo, para isso, ser ocupados por "médicos

\footnotetext{
${ }^{2} \mathrm{O}$ termo cunhado pelos autores relaciona-se a representação dos saberes médicos modernos e suas implicações como poder em um esquema de normalização da vida social brasileira a partir da reflexão e da intervenção sobre o espaço urbano e sua população. Dessa forma, apesar de não se opor radicalmente aos discursos denunciativos atuais sobre a "medicalização da vida"- esta que opera transformando questões de ordem social, política, cultural em distúrbios e transtornos, individualizando os desvios no campo das patologias e dos rótulos; refere-se propriamente a uma leitura histórica dos autores sobre o protagonismo assumido pelos saberes médicos na composição da sociedade brasileira nos séculos XIX e XX.
}

${ }^{3}$ MACHADO, ET AL, 1978, p. 43 
idôneos" formados na Universidade de Coimbra4 . Em 1744 foi estabelecido o regimento a ser observado pelos representantes da fisicatura no Brasil - órgão do governo português que regulamentava as práticas de cura em todo o Império- que objetivava regular os excessos e abusos que escapavam do controle da metrópole. Esse movimento foi acompanhado pela evolução dos interesses comerciais do reino com suas colônias, em que "o crescimento urbano e populacional autoriza um interesse maior com a "saúde dos povos"” (p. 30).

A prática médica articulada junto a organizações burocrático-administrativas, como a fisicatura, buscou regular o exercício da medicina, tanto com vistas a assegurar os interesses comerciais do reino decorrente do crescimento urbano e populacional ${ }^{5}$ como em virtude das demandas da população colonial por intervenções que minimizassem as mortes endêmicas da época. No entanto, a prática médica nesse período caracterizava-se por ser individual e curativa, sem incidência direta sobre a saúde da população ou a presença de intervenções que atingissem a totalidade da vida nas cidades. O serviço de hospitalização era caracterizado fundamentalmente pela atividade assistencial promovida pelos religiosos que compunham o quadro funcional das Santas Casas de Misericórdia espalhadas pela colônia, estas funcionavam em condições extremas de superlotação e inadequações de atendimento.

A presença de doenças endêmicas como a peste e a lepra promoveram a mudança desse cenário e juntamente com a transferência da capital do reino para o Rio de Janeiro, em 1763, e pela criação o vice-reinado, em 1775, assinala importantes mudanças quanto aos objetivos da administração imperial em relação à produção, à segurança e à saúde ${ }^{6}$ Daí decorre a difusão da ideia de que para combater as doenças seria necessário o estabelecimento de estratégias que abrangessem a população e a cidade.

O médico assume o papel de autoridade responsável pelas medidas de controle das cidades estruturando sua prática na relação entre saúde e sociedade, tendo como fio condutor o

\footnotetext{
${ }^{4}$ Até 1800 a profissão de médico foi vetada aos brasileiros, sendo, após esta data, nomeados poucos estudantes da província do Rio de Janeiro para estudar na Universidade de Coimbra, que possuía um ensino médico ineficiente e defasado. A chegada da família real em 1808 impulsionou a criação de instituições para a formação de "cirurgiões", estes eram responsáveis por sangrias, aplicações de sanguessugas, extrações dentárias e etc. permanecendo a formação médica restrita a Coimbra. A abertura dos portos às nações amigas possibilitou o acesso à bibliografia médica, até então restringidas pela metrópole, atenuando o problema da formação médica. A institucionalização da medicina no Brasil somente ocorreu em 1829 com a criação da Sociedade de Medicina no Rio de Janeiro, que produziu o Plano de Organização das Escolas Médicas do Império (MONTEIRO \& JACÓ-VILELA, 2006, grifos das autoras).
}

5idem1978, p. 21-105.

${ }^{6} \mathrm{Ibid}, \mathrm{p} 106$. 
tema da sujeira e necessidade de velar pela limpeza da cidade. Compreender a cidade a partir do ponto de vista da doença possível adquire significação mais profunda no quadro político da colônia dado que se relaciona com a defesa da riqueza e do território em que está sendo produzida. A importância da saúde da população recaía essencialmente na sua função de defender a terra e fazê-la produzir: "é nesse contexto que sujeira e doença articulam-se como binômio a ser evitado" (p.43).

Dessa forma, no início do século XIX um novo tipo de medicina buscou estabelecer e justificar sua presença na sociedade através da higiene pública, assumindo novos arranjos como saber e prática social. Aliada a interesses sócio-políticos de criação e fortalecimento da segurança e consequente manutenção do Brasil como colônia, a medicina se impõe pelo seu saber sobre a etiologia social das doenças, permitindo localizar e transformar os aspectos responsáveis pelo adoecimento da população ${ }^{7}$. Diante disso, a prevenção torna-se possível e é sob essa justificativa que o saber médico se expande e se insere nos espaços sociais e políticos.

\footnotetext{
Não é mais a ação direta e lacunar sobre a doença como essência isolada e especifica que move o projeto médico. O 'médico político' deve dificultar ou impedir o aparecimento da doença, lutando, ao nível de suas causas, contra tudo o que a sociedade pode interferir no bem-estar físico e moral [...] Se a sociedade, por sua desorganização e mau funcionamento, é causa de doença, a medicina deve refletir e atuar sobre seus componentes naturais, urbanísticos e institucionais visando a neutralizar todo perigo possível. Nasce o controle das virtualidades; nasce a periculosidade e com ela a prevenção (MACHADO et al, 1978, p.155).
}

Teve-se neste período a criação e reformulação dos regulamentos sanitários pelo controle de sua aplicação por médicos, intervenções em hospitais, prisões e outros lugares públicos, controle sobre a venda de medicamentos, estudos de endemias, criação de lugares de assistência a saúde dos pobres e etc.

Nomeia-se por "medicalização da sociedade" o reconhecimento da criação de uma nova tecnologia do poder médico, capaz de controlar os indivíduos, tornando-os produtivos e ao mesmo tempo inofensivos: "É a descoberta de que, com o objetivo de realizar uma sociedade sadia, a medicina social esteve, desde a sua constituição, ligada ao projeto de isolamento e transformação do desviante - sejam quais forem às especificidades que ele apresenta- em um ser normalizado"8 Técnicas de normalização que foram estratégicas no estabelecimento de um projeto de ordem social como critério de normalidade. A figura do médico, enquanto agente

\footnotetext{
${ }^{7}$ MACHADO, ET Al. 1978, p. 152-159

${ }^{8}$ MACHADO, Op Cit., p. 156.
} 
responsável por tratar aquilo que desviava do funcionamento normal do indivíduo atuava em diferentes instituições que se assemelhavam enquanto produtoras e possuidoras de "sistemas prescritivos de regularidades" (FOUCAULT, 2006; 2010).

É no seio da medicina social e do seu processo de medicalização da sociedade que nasce a psiquiatria como saber médico especializado sobre os desviantes e sobre a loucura, oferecendo justificativa médica para o seu controle. A patologização do comportamento do louco, considerado anormal, vez que desviava da norma social, possibilitou a emergência de um tipo específico de medicina para tratá-lo. Documentos da Sociedade de Medicina e Cirurgia do Rio de Janeiro, datados de 1830, ilustram que o mesmo grupo de médicos que promoveu a medicina social no país lançou a bandeira da psiquiatria ${ }^{9}$. Ao investigarem a situação dos loucos, expõem a sua periculosidade e propõem a criação de um espaço específico destinado para o seu abrigamento.

O hospício, principal instrumento terapêutico da psiquiatria, se estruturou após duras críticas às Santas Casas de Misericórdia, espaço até então destinado ao tratamento dos mais diversificados tipos de enfermidade. A precariedade das condições de abrigamento e tratamento destinado aos loucos contrariavam os preceitos da ciência médica, exigindo a criação de um novo espaço institucional. O hospício passa então a ser a grande evidência terapêutica da Psiquiatria, instituição capaz de medicalizá-los e recuperá-los, mas excluída do funcionamento e organização das cidades dado que representava um foco de perigos. Data de 1852 a criação do Hospício Pedro II, primeiro hospício brasileiro, construído na cidade do Rio de Janeiro (MACHADO, 1978).

No século XIX a loucura recebe definição médica de alienação mental, integrando o campo da psiquiatria. Os primeiros trabalhos sobre alienação mental no Brasil decorrem das teses apresentadas as Faculdades de Medicina do Rio de Janeiro e da Bahia, para a obtenção do grau de doutor, as quais ilustram tensões diante da originalidade do termo frente aos esquemas patológicos da época, tensões que se situaram entre o orgânico e o psíquico e entre o físico e o $\operatorname{moral}^{10}$.

As análises realizadas por Machado et al (1978) dos textos brasileiros sobre a loucura mostram o progressivo abandono do entendimento da loucura como perturbação estritamente intelectual para uma ênfase ao papel das paixões na doença mental. Diante da dificuldade de

${ }^{9}$ Ibid, p. 423

${ }^{10}$ MACHADO, Op. Cit. p. 384-410. 
localizar a relação entre o funcionamento desviante das faculdades mentais e a existência de uma lesão física cerebral, a intervenção médica se situou na "inteligência delirante da loucura", numa ação tanto moral quanto física:

O homem - frágil unidade físico-moral - é afetado pelas múltiplas e intensas relações com o mundo exterior e com outros homens. Para que esta trama de interações contínuas não o prejudique, a própria civilização produz uma arma: a ciência que, esclarecendo a educação, os costumes, etc., dá condições pra que desvios e excessos sejam prevenidos e corrigidos. A psiquiatria, ciência do homem, aparece como instrumento de aprimoramento da sociedade civilizada (p. 418).

Dessa forma, a medicina reclama o domínio sobre o louco, devendo a sua terapêutica e recuperação ser destinadas aos psiquiatras. Vinculada a um tratamento moral, a psiquiatria se expressou aliando interesses sociais e políticos a práticas médicas pretensamente científicas. É nessa seara que ao denunciar o funcionamento de várias instituições a psiquiatria trava sua batalha política de detentora do poder sobre o louco.

Com o crescente poder médico, a psiquiatria protagoniza embates com outros campos de saber, tal como o direito. Tendo como cenário o ideário iluminista, os princípios do direito clássico são estabelecidos e sistematizados segundo a ideia de livre arbítrio, a partir do qual todos devem ser responsabilizados pelos seus atos e serem punidos conforme a gravidade destes. A exceção ocorre àqueles com perturbações dos sentidos e da inteligência. Disso deriva que a verdade sobre os fatos antes revelada pela prova $^{11}$, deverá ser alcançada através de outro processo investigativo, o inquérito $^{12}$, segundo agentes capacitados na sua execução e identificação da loucura (JACÓ-VILELA et al, 2005).

No início do século XIX ainda se presentificam nas preocupações sobre o indivíduo criminoso e as razões dos seus delitos, ideais da moralidade civilizatória, mas é crescente o papel da ciência junto à necessidade de desvendar a verdade. Segundo Jacó-Vilela et al (2005) com o advento do direito positivo a ciência atinge o principal critério de verdade sobre os fatos. A objetividade requerida pelo direito positivo fez com que o interesse pelo criminoso e não pelo

\footnotetext{
${ }^{11}$ Foucault (1996) ao analisar a produção da verdade nas formas jurídicas, expõe a prova como o primeiro procedimento que marca o direito na Idade média e na Antiguidade. A prova no sistema jurídico feudal tratava-se não da pesquisa da verdade, mas de um "jogo de estrutura binária" em que ao indivíduo era facultada a sua aceitação ou renúncia. Seu fim é determinado por uma vitória ou por um fracasso, sendo a verdade confundida com a vitória do mais forte. A prova é de certa forma "automática", estabelecida sem recurso a sentenças ou a testemunhas. Dessa forma, não é necessária a presença de um terceiro para arbitrar sobre o seu desfecho, se existe uma autoridade é antes como testemunha da regularidade do procedimento (FOUCAULT, 1996, p. 47).

${ }^{12} \mathrm{O}$ inquérito marca a emergência de um novo processo investigativo com vistas a avaliar a verdade no interior da ordem jurídica, visa estabelecerquem fez o quê, em quais condições e em que momento, segundo a investigação da natureza dos fenômenos por agentes do saber (FOUCAULT, 1996).
} 
crime atingisse a prioridade no judiciário. Essa mudança tanto auxiliou a psiquiatria a se assumir enquanto saber e prática profissional especializada, como possibilitou o acirramento de novos conflitos:

O Direito Positivo significa o início de um período de disputa entre as instâncias jurídica e médica, pois parece haver uma exclusão mútua, uma tentativa de substituir um modo de controle pelo outro. Assim, há um problema de classificação em referência aos dois núcleos de saber: o réu é culpado ou louco? (p.15)

Entendendo o ato criminoso como um problema de intelecto, o poder psiquiátrico, através do seu saber especializado, passa a intervir sobre os sintomas da loucura e na cura da degeneração.

O final do século XIX é marcado pela circulação no Brasil dos trabalhos de Cesare Lombroso, criador da antropologia criminal. Este, apoiado na teoria da degenerescência de Morel $^{13}$, defendia que "o crime é um fenômeno natural do homem, devendo sua etiologia, eminentemente individual, ser estudada de modo que se possam constituir programas eficazes de prevenção" (JACÓ-VILELA et al, 2005, p.19). Afirmava a transmissão hereditária da criminalidade, explicando ainda o criminoso como uma subespécie humana, possuidor de traços degenerativos comportamentais, psicológicos e sociais.

Importa salientar que diante da nova percepção da visibilidade e periculosidade da loucura oferecida pela teoria lombrosiana, emergem os discursos preventivos com o objetivo de evitar a proliferação de determinados grupos sociais, tendo no hospício seu suporte institucional básico. Os discursos da Eugenia ${ }^{14}$ surgem nesse quadro social, se afirmando como proposta teórica e doutrina social capaz de regenerar a população moral e racialmente, ampliando o esquadrianhamento preventivo da vida urbana, numa clara intenção de controle social. Se a teoria da degenerescência foi o principal referencial teórico do alienismo brasileiro no século XIX, a partir do século XX este lugar foi ocupado pela eugenia o "equivalente moderno da degenerescência" (Cunha, 1986, p.166). Tal transição acentua a mudança da prática médica para a prevenção ao mesmo tempo em que aumenta as fronteiras da anormalidade.

\footnotetext{
${ }^{13}$ Morel defendea ideia da transmissão hereditária de uma predisposição do organismo à degenerescência. Esta pode ser provocada por condições físicas- insalubridade do clima, má higiene, insuficiência da moradia ou nutrição- ou morais- avareza, alcoolismo, prostituição, entre muitas outras. Como forma de intervenção nos casos de degenerescência Morel sugere a higiene moral, que deveria se empenhar na moralização dos comportamentos e a higiene física com modificações ambientais (JACÓ-VILELA, 2004).

${ }^{14} \mathrm{O}$ movimento protagonizado pela eugenia refere-se aos estudos dos fatores socialmente controláveis que podem beneficiar ou prejudicar as qualidades raciais das gerações futuras, tanto nos seus aspectos físicos quanto mentais (CUNHA, 1986).
} 
Na passagem da degeneração para a eugenia, o objeto central de atenção deixou de ser o louco ou o "semilouco" e passou a ser todo o corpo social, em especial, os operários urbanos. Para Cunha (1986) a perspectiva preventiva da higiene mental articulada aos princípios e as propostas da eugenia também contribuíram para a ampliação do campo de atuação da psiquiatria, através da reclusão de indivíduos que manifestassem os mais diversos comportamentos considerados moral e/ou socialmente perigosos ${ }^{15}$.

Tais acepções integraram o direito positivo que passou a rejeitar a noção de livre arbítrio sustentada pelo direito clássico e concentrou seu olhar sob o criminoso, no seu tratamento e regeneração.

Seus interesses são a investigação da subjetividade, da interioridade dos criminosos, além de definir os meios adequados de tratamento para transformá-los em cidadãos disciplinados e obedientes, visto que os métodos anteriores, pretendendo somente punir o crime, não surtiam efeito educativo sobre o criminoso. A pena tem, pois, o caráter duplo de recuperação do indivíduo e de proteção social (JACÓ-VILELA et al, 2005, p.21).

Como recurso à execução dos novos princípios do direito positivo elegeu-se a técnica do inquérito, método que possibilita "abstrair elementos comuns e criar classificações" 16, e do exame, que permite "o escrutínio detalhado, revelador do mundo interno de cada um" 17. O exame psiquiátrico operaria dentro das instituições judiciárias enquanto discurso de verdade, formulado por agentes "qualificados" e "possuidores de estatuto científico".

Enquanto dispositivo de poder, o exame psiquiátrico permite a substituição do delito, tal como é qualificado pela lei, em uma série de outros elementos que são apresentadas como causa, origem e motivação do delito; estes se constituirão na prática judiciária como a própria matéria punível. Nesse sentido, a análise da conduta delituosa ultrapassa a seara legal, figurando como regras éticas e qualificações morais. O exame psiquiátrico permite constituir esse "duplopsicológico-ético do delito", uma propriedade de fazer aparecer, por trás das condutas delituosas,

\footnotetext{
${ }^{15}$ A Liga Brasileira de Higiene Mental- LBHM, criada em 1923, conjugou ao longo do tempo objetivos ligados tanto à busca pela melhoria da assistência psiquiátrica, quanto à atenção a higiene mental, alinhada a um tipo de intervenção médico-social com indicação preventivas e eugênicas. Imbuídos pelo espírito nacionalista e "regeneracionista" elegeram certos casos como prioritários na tarefa de garantir "a defesa da mentalidade da raça", como: combate ao alcoolismo e vícios sociais, imigração, controle dos casamentos- para impedir as uniões indesejáveis e promover a união dos eugenicamente desejáveis, esterilização compulsórias dos ditos degenerados, atenção a infância para o desenvolvimento mental sadio e eugênico, dentre outros. Em verdade, todos esses temas visavam o "melhoramento da raça brasileira", visto como fundamental para transformar o Brasil em nação (CUNHA,
} 1986, grifos da autora).

16 Jacó-Vilela, et al, 2005, p.21

${ }^{17}$ Idem, p. 21

Barbarói, Santa Cruz do Sul, n. 52, p.<22-47>, jul/dez, 2018 
irregularidades em relação a regras morais, psicológicas, fisiológicas, etc. (FOUCAULT, 1977; 2006).

Dessa forma, o papel principal do exame psiquiátrico é legitimar, enquanto conhecimento científico, a extensão do poder de punir para além da infração e qualificar o autor do crime com base nos seus antecedentes. Como desdobramento dessa função, tem-se o exame psiquiátrico como principal elemento de demonstração da criminalidade possível; uma clara contribuição para fazer o indivíduo passar da condição de réu para a de criminoso, na medida em que os exames permitem o rastreio das suas 'anormalidades'. O exame psiquiátrico trata-se, portanto, de uma técnica de normalização, controle e apreciação que se apoia na instituição médica e judiciária para se exercer e fracionar o poder legal de punir.

É através dessas transformações que o psiquiatra passa a ocupar um lugar dentro do sistema jurídico: enquanto profissional com expertise para qualificar o indivíduo, capaz de uma apreciação de normalidade e uma prescrição técnica para uma normalização possível (tratamento). Nesse sentido, passa a operar dando aos mecanismos legais de punição um poder justificável, não somente sobre as infrações, mas sobre os indivíduos e aquilo que eles são. As punições figuram agora como mecanismos que:

\footnotetext{
Não se destinam a sancionar a infração, mas a controlar o individuo, a neutralizar a sua periculosidade, a modificar suas disposições criminosas, a cessar somente após a obtenção de tais modificações. A alma do criminoso não é invocada no tribunal somente para explicar o crime e introduzi-la como atribuição jurídica das responsabilidades; se ela é invocada com tanta ênfase, com tanto cuidado de compreensão e tão grande aplicação 'cientifica' é para julgá-la ao mesmo tempo que o crime, e fazê-la participar da punição (FOUCAULT, 1977, p.22).
}

A punição, vista agora com função de reeducar, corrigir e curar; marcou a prática penal com alterações quanto aquilo que constitui o elemento punível. O objeto crime foi profundamente modificado. Julgam-se agora, para além dos atos praticados, as paixões, os instintos, as anomalias e inadaptações. No entanto, como salienta Foucault (1977): "Dir-se-ia que não são eles que são julgados; se são invocados é pra explicar os fatos a serem julgados e determinar até que ponto a vontade do réu estava envolvida no crime" (p. 21). Argumento insuficiente na medida em que são esses elementos por trás do ato que são, na realidade, julgados e punidos.

Esses efeitos também ressoaram em outros domínios como na composição familiar e sobre a infância. No cenário nacional, é possível perceber a presença desses elementos nas 
discussões sobre o pátrio poder ${ }^{18}$ e a inexistência de tribunal para menores ${ }^{19}$. A atenção sobre as famílias decorreu da noção de que diferentes condições de desordens familiares poderiam consistir em causas da degenerescência e, consequentemente, da criminalidade. No que se refere à inexistência de tribunais especiais para menores no Brasil ou estabelecimentos de recolhimento e educação para menores, a preocupação decorria da impossibilidade da institucionalização e recuperação dos jovens criminosos e dos moralmente abandonados.

Vale ressaltar que, até meados do século XIX, o termo menor demarcava apenas a idade das responsabilidades civis. No que se referia aos delitos praticados, eram punidos como adultos, figurando a idade apenas como atenuante nas condenações de pena de morte. Os menores abandonados eram nomeados órfãos ou expostos e eram abrigados em instituições caritativas mantidas pela Irmandade da Misericórdia (ARANTES, 2011). O problema do menor no início da República se refere justamente a uma nova categoria que se apresenta: a das "crianças órfãs de pais vivos e futuros criminosos" (p. 23). Diante desse contexto, compõem a assistência pública aos menores projetos de caráter correcional e preventivo; legitimados como mecanismos de garantia da justiça diante dos riscos sociais e de ruptura da norma.

Ao longo de quase todo século XX vigorou uma corrente de preocupações sobre a destinação da infância desadaptada e das crianças difíceis. Em 1923, tem-se a criação do primeiro Juizado de Menores do Brasil, no Rio de Janeiro, instituição que se destinava ao tratamento tanto de crianças e menores abandonados, como menores criminosos ou que possuíssem determinadas heranças biológicas afeitas à degenerescência. Ao médico cabia estabelecer o tratamento com vistas a identificar os fatores causais e à recuperação do comportamento delinqüente (SILVA, 2011). É sobre os domínios de uma infância desaptada que será realizado os primeiros exames psicológicos nos domínios jurídicos.

\section{A Psicologia Jurídica brasileira em curso}

Em 1930, o Laboratório de Biologia Infantil passa a compor o Juizado de Menores do Brasil. As atividades desenvolvidas no Laboratório relacionavam-se primariamente às práticas

\footnotetext{
${ }^{18} \mathrm{O}$ termo 'pátrio poder', que estabelece o homem como detentor exclusivo do poder de decisão sobre questões familiares foi substituído por 'poder familiar' na Constituição Federal Brasileira de 1988 e no novo Código Civil de 2002, como forma de estabelecer igualdade de direitos e deveres para homens e mulheres.

${ }^{19}$ Termo também em desuso, mas que será utilizado com vistas a demarcar sua historicidade e o movimento sóciopolítico que representou.
}

Barbarói, Santa Cruz do Sul, n. 52, p.<22-47>, jul/dez, 2018 
dos médicos legais quanto à identificação e classificação das crianças e jovens abandonados e infratores, ainda baseados em preceitos higienistas (Silva 2011, p. 56). Com a mudança da diretoria administrativa, em 1938, novos agentes passaram a integrar o quadro de profissionais e novos procedimentos começaram a ser adotados. Os exames de psicologia, pedagogia e clínica médica figuraram nesse espaço com vistas à instrumentalização da medicina e no desenvolvimento de atividades assistenciais.

Dessa articulação, surge o profissional psicologista, responsável por realizar "testes de identificação" no Laboratório de Biologia Infantil do Juizado de Menores, e que em 1940, ocuparia também o Manicômio Judiciário do Rio de Janeiro (JACO- VILELA et al, 2005). Estes profissionais eram responsáveis por dar subsídios concretos aos psiquiatras quanto à inimputabilidade dos réus e a determinação da sua periculosidade, e o faziam através dos testes psicológicos, enquanto dispositivos técnicos capazes de indicar anomalias e desvios. É possível demarcar nessa articulação a primeira incursão formal da psicologia jurídica brasileira junto aos aparelhos de justiça.

A obra "Manual de Psicologia Jurídica", de Mira y López, edição argentina de 1945, consistiu no primeiro referencial técnico sobre a área a circular nacionalmente. Os autores definiram a psicologia jurídica como a psicologia aplicada ao melhor exercício do direito, conceituação que sinaliza o caráter acessório e instrumental da psicologia ao exercício do direito, característico do período inicial do desenvolvimento desse campo de atuação, mas que também ilustra a importância da higiene mental como forma preventiva da criminalidade ${ }^{20}$.

A articulação entre psicologia e direito em termos de atuação profissional teve o seu protagonismo com a nomeada 'psicologia do testemunho' que objetivava verificar, através de estudos empíricos dos processos psicológicos, sobretudo, com a utilização de testes psicológicos, a veracidade do relato das testemunhas. Tal articulação ilustra a psicologização em curso, não só o criminoso deve ser examinado, mas todos aqueles que viram e relataram o que viram ${ }^{21}$. Essa fase inicial foi marcada por fortes influências do ideário positivista, que privilegiava o método científico utilizado pelas ciências naturais. Foi principalmente na perspectiva do exame, da busca pela 'verdade psíquica', que a psicologia se aproximou do direito (ANASTASI, 1972). Essa relação ainda se mostra bastante atual e será melhor discutida na sessão seguinte.

${ }^{20}$ JACÓ-VILELA et al, 2005.

${ }^{21} \mathrm{i}$ dem, p. 28 .

Barbarói, Santa Cruz do Sul, n. 52, p.<22-47>, jul/dez, 2018 
Dessa forma, pode-se afirmar que a prática profissional do psicólogo jurídico consistiu inicialmente na realização de exames, pareceres e perícias psicológicas, que ilustram a aplicação dos saberes da psicologia e de seus instrumentos junto às instituições jurídicas na busca pela verdade e pela caracterização comportamental dos desviantes (BRITO, 2005, 2012a, ALTOÉ, 2001). As informações fornecidas pelos psicólogos, sendo estas pautadas em comportamentos e situações aferidas ou observáveis, subsidiariam condução do processo jurídico.

Em âmbito nacional, a atuação dos psicólogos junto à Justiça foi gradativamente se alargando e se caracterizou pela realização de trabalhos nas varas da infância, criminais e da família, em uma prática prioritariamente voltada para elaboração do psicodiagnóstico, sob o modelo pericial (Brito, 2012a., Lago et al, 2009). Para os operadores do direito a realização do psicodiagnóstico culminaria no levantamento de dados matematicamente comprováveis, originários da aplicação de instrumentos técnicos, e que, portanto, seriam capazes de fornecer diagnósticos precisos. Como herança dos modelos periciais médicos, esperava-se por um parecer técnico-científico com diagnósticos no campo da psicopatologia para fundamentar decisões jurídicas.

Em 1962, com a regulamentação do exercício profissional, a psicologia jurídica foi gradualmente sendo reconhecida como campo de atuação dos psicólogos. Foi com a promulgação da Lei de Execução Penal (Lei Federal $n^{\circ}$ 7.210/84) que o profissional em psicologia, que comporia a Comissão Técnica de Classificação das penas, passou a ser reconhecido legalmente pela instituição penitenciária. Como consta no artigo $7^{\circ}$ da legislação:

Art. $7^{\circ}$ - A Comissão Técnica de Classificação, existente em cada estabelecimento, será presidida pelo diretor e composta, no mínimo, por dois chefes de serviço, um psiquiatra, um psicólogo e um assistente social, quando se tratar de condenado à pena privativa da liberdade.

As atribuições da comissão consistiam na realização de classificações dos regimes penais, a partir da construção do programa individualizado e o acompanhamento da execução das penas, devendo propor à autoridade competente progressões e regressões dos regimes, bem como as conversões do tipo de encarceramento (BRITO, 2012). Em 1984, com a edição da Lei de Execução Penal, institui-se também a realização da avaliação criminológica. Daí resultou-se o Centro de Observação Criminológica que, diferentemente da Comissão Técnica de Classificação - que tinha como objetivo avaliar o cotidiano dos condenados-, era responsável pela realização de exames periciais e pesquisas criminológicas que retratariam o 'perfil' do preso, enquanto 
instrumento de auxílio nas decisões judiciais. O sistema progressivo se estabelecia com base na avaliação da ressocialização do preso, eram avaliadas a sua adaptação à dinâmica institucional e às regras e se submetia satisfatoriamente ao tratamento penal (CARVALHO, 2011).

Ainda na década de 60 essas atribuições foram alvo de contestações quanto à legitimidade dos estudos produzidos e quanto à presença de julgamentos morais. "A categoria ressocialização, encarada como índice de valoração da vida do periciando, invariavelmente cedeu espaço à violação da intimidade, em decorrência da possibilidade da avaliação e do julgamento morais da história pessoal e das opções de vida do ‘objeto’ de análise” (CARVALHO, 2014, p. 185). Nesse ensejo, insidiosamente, foram surgindo discussões acerca da prática do psicólogo jurídico junto a eventos promovidos pelos Conselhos de Psicologia, debate que se mantém até os dias atuais.

Nos anos 80 aconteceu o primeiro concurso para o cargo de psicólogo junto ao Poder Judiciário em São Paulo. Os cargos criados destinavam-se a atuações nas Varas da Infância, até então denominadas Varas de Menores, e nas Varas de Família. Com a implantação do Estatuto da Criança e do Adolescente (ECA), em 1990, o Juizado de Menores foi renomeado Juizado da Infância e Juventude, em virtude de uma nova proposta de ação ${ }^{22}$. A partir disso, houve igualmente a ampliação do trabalho do psicólogo junto às demandas da área, envolvendo não apenas a atividade pericial, como também o acompanhamento de medidas de proteção, de garantia de direitos, processos de adoção, de institucionalização, dentre outros. A ampliação do campo de atuação do psicólogo culminou na criação de novas vagas em instituições judiciárias e na disseminação de concursos para a categoria em diferentes regiões do país (BRITO, 2012; LAGO, et al, 2009).

Em virtude da ampliação do campo e com fins de orientar os profissionais que atuavam em psicologia jurídica, em 1986 teve-se a criação do primeiro curso de especialização em psicologia jurídica, na Universidade Estadual do Rio de Janeiro- UERJ (ALTOÉ, 2001). O curso que inicialmente se centrava no estudo de técnicas e instrumentos para a realização do psicodiagnóstico no âmbito jurídico sofreu diversas reformulações ao longo dos anos.

\footnotetext{
${ }^{22}$ A década de 80 foi marcada por uma abertura democrática com intensos debates sobre Direitos Humanos no Brasil, incluindo discussões sobre os direitos da criança e do adolescente. Antecipando-se à Convenção das Nações Unidas sobre Direitos da Criança, realizada em 1989, a Constituição da República de 1988 rompeu definitivamente os paradigmas da Situação Irregular, sustentada pelo Código de Menores (Lei Federal $n^{\circ}$ 6.697/79)- que regulava medidas sobre casos de delinquência, vitimização e pobreza das crianças e dos adolescentes- ao estabelecer o princípio da Proteção Integral no ordenamento jurídico, posteriormente regulamentada pelo Estatuto da Criança e do Adolescente - ECA (Lei Federal $n^{\circ}$ 8.069/90). Com o advento do ECA a criança e o adolescente passam a ser vistos como sujeitos possuidores de todos os direitos fundamentais inerentes à pessoa humana, sem prejuízo da proteção integral, e pelo reconhecimento da sua condição peculiar de pessoas em desenvolvimento (RIZZINI, 2000).
} 
Atualmente é ofertado com mudanças significativas na sua proposta e estrutura curricular, adotando uma configuração crítico-reflexiva sobre a atuação do psicólogo frente às demandas jurídicas.

No cenário dos anos 90, imperou discussões sobre a criação de novas vagas para psicólogos no judiciário e juntamente a este interesse, discussões sobre a atuação profissional e seu caráter até então essencialmente pericial (BRITO, 2012a).

Em 1999, foi realizado o III Congresso Iberoamericano de Psicologia Jurídica, em São Paulo. O evento, de nível internacional, contou com diversos nomes importantes e se caracterizou como marco nacional na área por ser a única edição sediada no Brasil e por possibilitar, ainda que preliminarmente, uma demarcação dos principais temas de interesse dos psicólogos jurídicos brasileiros, o caráter das suas atuações e o entendimento dos fenômenos por eles trabalhados ${ }^{23}$.

França (2004) produziu o levantamento e análise dos trabalhos que compuseram os Anais do III Congresso Ibero-Americano de Psicologia Jurídica como forma de traçar o panorama e os principais campos de investigação da psicologia jurídica no Brasil. De modo geral, os trabalhos apresentados se estruturaram em dois eixos: o primeiro, destinado a trabalhos relacionados a setores tradicionais da psicologia jurídica, e o segundo, a setores mais recentes, no que se refere à prática profissional e às produções bibliográficas. Os trabalhos que compuseram o primeiro eixo referiram-se a temas como: Psicologia Criminal; Psicologia Penitenciária; Psicologia Jurídica e as questões da infância e juventude; Psicologia Jurídica e Direito de Família; Psicologia Jurídica: investigação, formação e ética; Psicologia do Testemunho; Psicologia Jurídica e Direito Civil e Psicologia Policial/Militar. O segundo eixo foi composto por trabalhos que se relacionavam com Mediação; Psicologia Jurídica e Ministério Público; Psicologia Jurídica e Direitos Humanos; Dano psíquico; Psicologia Jurídica e Magistrados; Proteção a Testemunhas e Vitimologia.

A análise produzida pela autora constatou maior concentração de produções acadêmicas nos setores tradicionais, sugerindo uma centralidade em práticas já consolidadas e legitimadas no campo, que historicamente apresentam uma relação íntima com a atividade pericial no atendimento das demandas jurídicas. Quanto às produções que se relacionavam aos setores recentes na psicologia jurídica, inferiu-se que os trabalhos ainda incipientes se referem tanto às

\footnotetext{
${ }^{23} \mathrm{O}$ referido evento demandou a articulação de psicólogos jurídicos brasileiros de diferentes setores na sua organização prévia objetivando sediá-lo no país. Tal articulação contribuiu para a criação da Associação Brasileira de Psicologia Jurídica, oficializada em 1998.
} 
práticas emergentes ${ }^{24}$ como a falta de produção e publicação bibliográficas do que tem sido feito na área. A autora conclui salientando a importância da produção do conhecimento científico tanto para respaldar a prática social como para estabelecer, em níveis metodológicos e epistemológicos, uma psicologia jurídica brasileira.

Vale ressaltar que, em 2014, aconteceu o $1^{\circ}$ Congresso Ibero-americano de Psicologia Forense, evento realizado por um grupo de profissionais da região sul do Brasil ${ }^{25}$. O evento objetivou a circulação das produções científicas e práticas em psicologia forense - nomeação escolhida dado a sua utilização nos periódicos norte americanos - e ainda, a criação da Associação Ibero-americana de Psicologia Forense.

Atualmente, os psicólogos jurídicos brasileiros estão inseridos em diversos órgãos públicos, como os Tribunais de Justiça, Ministérios Públicos Estaduais, Defensorias Públicas, penitenciárias, em instituições de cumprimento medidas socioeducativas para adolescentes e etc., nos quais o ingresso se dá, na maior parte dos casos, através da aprovação em concursos públicos. Há ainda, profissionais que não estão lotados nessas instituições, mas que são contratados para executar trabalhos para o sistema de Justiça. Inserem-se nesse contexto psicólogos clínicos e profissionais que compõem equipe em instituições, como ONG's, Conselhos Tutelares, CREAS, dentre outras.

A psicologia jurídica, vista atualmente como uma especialidade da psicologia, vivencia dificuldades como a predominância de práticas avaliativas e periciais de subsídio aos operadores do direito e a inexistência de uma epistemologia própria, que acaba por fragilizar as atuações profissionais, no que se refere à ausência de um projeto que confira uma unidade às diferentes demandas destinadas aos profissionais da área e às práticas executadas. Como apresentado por Canguilhem (1999), essa fragilidade pode ser percebida na ciência psicológica como um todo e a sua superação requer um constante retorno ao passado para investigar as relações que se sobrepuseram à emergência desse campo, assim como a análise dos projetos que se interceptam e o sentido de cada um deles, analisando criticamente as situações que o fizeram emergir.

Nesse sentido, a breve e fragmentada elucidação de certos caminhos trilhados pela psicologia jurídica brasileira em suas articulações sócio-políticas e científicas apresentadas

${ }^{24}$ Órgãos representativos da categoria dos psicólogos se dedicaram ao longo dos anos ao estudo do alcance e dos limites das práticas profissionais diante das novas demandas do mercado e quanto à formação profissional ofertadas nas universidades. Dessa forma,o termo "práticas emergentes" demarca o rastreamento das novas possibilidades de atuação em psicologia a partir das demandas sociais.

${ }^{25}$ Maiores informações sobre o evento disponível no site:<http://www.iberoforense2014.com.br>

Barbarói, Santa Cruz do Sul, n. 52, p.<22-47>, jul/dez, 2018 
objetivou relacionar as diversas condições de produção dos seus saberes e práticas sociais, remetendo ao conjunto das condições históricas que os tornaram possíveis. De forma análoga, recorreu-se também a historicidade da psicologia jurídica para evidenciar como esta operou nas redes de poder, se estabelecendo em vários pontos do funcionamento social por meio de diferentes procedimentos e com eficácia regulada a partir de objetivos diversificados.

\section{Considerações Finais}

O presente trabalho, ao demarcar o desenvolvimento da psicologia jurídica brasileira no entrecruzamento de saberes médicos e jurídicos, especificamente na relação da psiquiatria com a criminologia, consistiu em uma primeira incursão no estudo da história dos saberes e seus efeitos nas redes de poder. A utilização de análises genealógicas como estratégia analítica possibilitou revisitar a consolidação dos saberes e políticas criminais na problemática mais geral da organização social brasileira, especialmente, dos séculos XVIII ao início do século XX, sem, contudo, pretender explicar a sua totalidade ou tudo explicar a partir desse movimento. Assim, os aspectos escolhidos ao longo da construção desse trabalho o foram por virem marcando as práticas e saberes que compõem a psicologia jurídica e dada à intenção em contribuir para a crítica dos seus arranjos no presente.

A breve elucidação da história da medicina no Brasil permitiu analisar a relação estabelecida entre a consolidação desse campo de conhecimento e a emergência de determinadas tecnologias de poder. A aliança com o discurso criminológico, especificamente, criou as condições de possibilidades para a emergência de práticas avaliativas e diagnósticas que possibilitaram o surgimento e a consolidação da psicologia jurídica como prática profissional e campo de saber. Esta, que inicialmente figurou como tecnologia disciplinar, também produziu efeitos no que se refere a um papel político social no judiciário brasileiro.

Foi possível também rastrear e discutir às problematizações que compuseram os discursos da medicina social, da psiquiatria e da criminologia, circulantes no cenário brasileiro do século $\mathrm{XX}$, junto ao julgamento das paixões, dos instintos, dos afetos, das enfermidades, das

inadaptações, dos efeitos do meio e da hereditariedade que caracterizariam o criminoso, ressoando num novo regime de penalidades a ser estabelecida a partir do tipo de anormalidade da 
qual padeceria o criminoso e sob a justificativa de cura e recuperação. As considerações tecidas indicaram como a psicologia jurídica brasileira, intimamente vinculada a dispositivos de poder, também se consolidou a serviço do controle social e da normalização dos indivíduos

Dessa forma, ao inserir a psicologia jurídica nas redes de poder no entrecruzamento da psiquiatria e criminologia, buscou-se explicitar os elementos que a compuseram e seus efeitos nos esquemas de normalização da vida que ainda se apresentam na realidade social brasileira, através da instrumentalização de técnicas e procedimentos "científicos" que mais se assemelham a reguladores e controladores "técnicos" em nome da defesa social. Estes ao serem confrontados com os novos discursos de transgressão, mascaram-se ora com mais repressividade ligada a aspectos institucionais e normativos, ora através de sutilezas que integram os discursos científicos 'humanizadores'.

Assim, ao balizar a relação entre os dispositivos de poder e jogo da verdade, segundo articulações históricas, suas implicações e efeitos sociais, foi observado que a psicologia jurídica brasileira conserva muitos aspectos dos aspectos que permitiram a sua emergência. No entanto, um movimento recente parece compor esse campo de saber e de atuação que ao menos em parte, reconhece seus efeitos ético-políticos e a importância problematizar suas implicações. Dessa forma, um segundo momento de enfrentamento se apresenta, esse diagnóstico preciso do presente ainda está por se fazer.

\begin{abstract}
Initially intended as an auxiliary knowledge to the practice of justice, legal psychology was structured in Brazil from the dual medical and judicial qualification game, in which the figure of the criminal person came to prevail over the appreciation of the crime itself, a movement that joined disciplinary and legal practices to the medical, psychiatric and psychological. The present work seeks to demarcate in the historical route of development of psychology and criminology throughout a disciplinary and normalizer corporate project which reflected in the increase of the diagnostic and evaluative activities, still today considered as the main activities addressed to legal psychologists. In attempt to promote reflections and make possible new analyzes on the theme, the relations between knowledge and power in the process of urge and structuration of legal psychology in Brazil are questioned through the perspective of certain analysis made by Michel Foucault. This is mainly an attempt to use some conceptual elements build by the author as tools for a critical analysis of the relations between knowledge competences and power practices assumed by legal psychology in Brazil, as well as questioning its social regimentations and political urgencies as knowledge and new technology of power produced in the modern era.
\end{abstract}

Keywords: Juridical Psychology, Psychiatry, Criminology Resumen 
La psicología jurídica se estructuró en Brasil a partir del juego de doble calificación médica y judicial en que la figura del criminal pasó a prevalecer sobre la apreciación del delito, movimiento que unió prácticas disciplinarias y jurídicas. El presente trabajo busca demarcar en el recorrido histórico de desarrollo de la psicología jurídica brasileña sus articulaciones junto a saber como la psiquiatría y la criminología a largo de un proyecto societario disciplinario y normalizador que reflejó en el aumento de las actividades diagnósticas y de evaluación, aún hoy las principales actividades dirigidas a los psicólogos jurídicos. En el intento de promover reflexiones y posibilitar nuevos análisis sobre el tema, son problematizadas en este trabajo las relaciones entre saber-poder en el proceso de emergencia y estructuración de la Psicología Jurídica en Brasil a partir de ciertos análisis producidos por Michel Foucault. Se trata, principalmente, de un intento de utilizar algunos de los elementos conceptuales construidos por el autor como dispositivos para un análisis crítico de las relaciones entre prácticas de conocimiento y prácticas de poder asumidas por la psicología jurídica brasileña, problematizando sus regulaciones sociales y urgencias políticas como saber y nueva tecnología de poder producida en la modernidad.

Palabras-clave: Jurídical Psychología, Psiquiatría, Criminología

\section{Referências Bibliográficas}

ALtoÉ, S. Atualidade da Psicologia Jurídica. Revista de Pesquisadores da Psicologia no Brasil. Juiz de Fora, Ano 1, No 2, julho-dezembro, 2001.

ANASTASI, A. Campos da psicologia aplicada.São Paulo: Herder, 1972.

ARANTES, E.M.M. Pensando a psicologia aplicada à justiça. In: BRANDÃO, E. P. \& H.S. GONÇALVES. Psicologia jurídica no Brasil. $3^{\circ}$ Ed. Rio de Janeiro: NAU Editora, 2011, p.1549.

BRANDÃO, E. P. \& H.S. GONÇALVES.Psicologia jurídica no Brasil. $3^{\circ}$ Ed. Rio de Janeiro: NAU Editora, 2011, 349p.

BRITO, L, M, T. Reflexões em torno da Psicologia Jurídica. In: CRUZ, R. M.; MACIEL, S. K. e RAMIREZ, D. C. O trabalho do psicólogo no campo jurídico. São Paulo: Casa do Psicólogo, 2005, p. 9-17.

Anotações sobre a psicologia jurídica. Psicologia: Ciência e Profissão, 32(spe), 2012,

p. $194-205$. 
BRITO, L.M.T. BEIRAS, A. \& OLIVEIRA, J.D.G. Psicologia Jurídica: reflexões críticas sobre demandas emergentes e exigências profissionais. Quaderns de Psicologia, Vol. 14, n 2, 2012, p. 25-36.

CAIRES, M. A. F. Psicologia Jurídica: implicações conceituais e aplicações práticas. São Paulo: Vetor, 2003. 205p.

CANGUILHEM, Que é a Psicologia? Revista Impulso, 11(26), 1999 (Trabalho original publicado em 1958), p. 11-26.

CARVALHO, S. O papel da perícia psicológica na execução penal. In: BRANDÃO, E. P. \& H.S. GONÇALVES.Psicologia jurídica no Brasil. $3^{\circ}$ Ed. Rio de Janeiro: NAU Editora, 2011, p.175250.

COIMBRA, C. M. Direitos humanos e a atuação na área jurídica. In: CNDH- CFP, Os direitos humanos na prática profissional dos psicólogos. Brasília, 2003.

CRUZ, R. M. A Perícia Psicológica. In: CRUZ, R.M., ALCHIERI, J. C., SARDÁ, J. J. Avaliação e Medidas Psicológicas. São Paulo: Casa do Psicólogo, 2002, p. 263-274

CUNHA, M. C. P. O espelho do mundo: Juquery, a história de um asilo. Rio de Janeiro: Paz e Terra, 1986.

FOUCAULT, M. A verdade e as formas jurídicas. Rio de Janeiro: Ed. Nau, 1996.

. Vigiar e Punir: Nascimento da prisão. Petrópolis: Vozes, 1977, 280p.

A microfísica do poder.Rio de Janeiro: Edições Graal, 1979.

. O poder psiquiátrico: Curso dado no Collège de France (1973-1974). São Paulo: Martins Fontes, 2006.

Os anormais: Curso no Collège de France (1974-1975). São Paulo: Martins Fontes, 2010.

FRANÇA, F. Reflexões sobre Psicologia Jurídica e seu panorama no Brasil. Psicologia: Teoria e Prática, 6 (1),2004, p. 73-80.

GAVA, L. L. Perícia psicológica no contexto criminal em casos de suspeita de abuso sexual infanto-juvenil. Tese de doutorado não-publicada, Programa de Pós-Graduação em Psicologia, Universidade Federal do Rio Grande do Sul, 2012, 112p. 
JACÓ- VILELA, A.M. et al. Os estudos médicos no Brasil no século XIX: contribuições à Psicologia.Memorandum, 7, 2004, p.138-150.

- Medicina Legal nas teses da faculdade de medicina do Rio de Janeiro (1830-1930): O encontro entra Medicina e Direito, uma das condições de emergência da Psicologia Jurídica. Interações, Vol. X, n.19, 2005, p. 9-34.

JESUS, F. Breve histórico da psicologia jurídica. In: JESUS, F. Psicologia aplicada à justiça. Goiânia: AB Editora, 2000, p. 27-30.

LAGO,V. L. et al. Um breve histórico da psicologia jurídica no Brasil e seus campos de atuação. Estudos de Psicologia.Campinas 26(4), 2009, p. 483-491.

MACHADO, R.et al. Danação da norma: a medicina social e constituição da psiquiatria no Brasil. Rio de Janeiro: Edições Graal, 1978, 559p.

MACHADO, R. Introdução: Por uma genealogia do poder. In: Microfísica do Poder. Rio de Janeiro: Graal, 1979, p. VII-XXIII.

MONTEIRO, D. B. \& JACÓ- VILELA, A. M. Fios, seduções e olhares: os primórdios 'psi' nas terapias para corpos e mentes perturbados.In: JACÓ-VILELA, A. M., FERREIRA, A. L. \& PORTUGAL, F. T. (Orgs.) História da Psicologia - rumos e percursos. Rio de Janeiro: Nau, 2006, p.141-158.

RAUTER, C. Criminologia e Subjetividade no Brasil. Rio de Janeiro: Revan, 2003, 128p.

RIZZINI, I. A criança e a lei no Brasil - revisitando a história (1822-2000). Brasília, DF; Rio de Janeiro: UNICEF; USU Editora Universitária, 2000, 142p.

ROVINSKI, S, L, R \& CRUZ, R.M. Psicologia Jurídica: perspetivas teóricas e processos de intervenção.1ed, São Paulo: Vetor, 2009, p 11-43.

. Fundamentos da perícia psicológica forense. São Paulo: Vetor, 2007, 175p.

. ROVINSKI, S. L. R. Perícia psicológica na área forense. In Cunha, J. A. e cols. Psicodiagnóstico V, Porto Alegre: Artmed, 2000, p. 183-195.

SILVA, D. M. P. Psicologia Jurídica no Processo Civil Brasileiro: a interface da psicologia com direitos nas questões de família e infância. São Paulo: Casa do Psicólogo, 2003, p. 5-30.

SILVA, R. O Laboratório de Biologia Infantil, 1935-1941: da medicina legal à assistência social. História, Ciências, Saúde - Manguinhos, Rio de Janeiro, v.18, n.4, out-dez, 2011, p.1111-1130. 


\section{Sobre os autores}

Rafaela de Sousa Caldas é mestre na linha de Bases Históricas, Teóricas e Políticas da Psicologia na Universidade Federal de Goiás. Endereço eletrônico: rafaelacaldas6@ gmail.com.

Tiago Cassoli é professor adjunto da Universidade Federal de Goiás- UFG regional Jataí e no Programa de Pós-graduação em Psicologia da UFG regional Goiânia, doutor na área de Psicologia e Sociedade. Endereço eletrônico: cassolitiago@yahoo.com 